Est Ag 52 (2017) 601-610

\title{
Representación de San Pablo en el arte vallisoletano
}

\author{
ENRIQUE GARCÍA MARTÍN
}

RESUMEN: En comparación con el resto de los apóstoles, la figura de San Pablo tiene muy pocas representaciones a lo largo de la Historia del Arte. Esto se manifiesta en la ciudad de Valladolid donde su manifestación se da en contables veces y en una calidad regular. A pesar de ello, en sus escasas apariciones, figuran nombres de artistas como Francisco del Rincón, Juan de Ávila o Antonio Villabrille, nombres unidos a la escultura barroca tan importante en la ciudad.

PALABRAS ClAVE: Representación artística; Leyenda Dorada; Iconografía; Escultura exenta; Retablo; Pintura.

ABSTRACT: Compared with the rest of the apostles, the figure of St. Paul has very few representations throughout the History of Art. This is manifested in the city of Valladolid, where its manifestation is given on rare occasions and in a regular quality. In spite of this, in his few appearances, they include names of artists like Francisco del Rincón, Juan de Ávila or Antonio Villabrille, names united to the baroque sculpture so important in the city.

KEYWORDS: Artistic representation - Golden Legend - Iconography - Sculpture Altarpiece - Painting.

Nadie pone en duda la importancia teológica y escriturística que ha supuesto en la historia del cristianismo la figura de Pablo de Tarso. Sin embargo no sucede lo mismo en lo que se refiere a la religiosidad popular y por ende a su representación artística.

En efecto, si comparamos las infinitas esculturas, pinturas, miniaturas... en las que aparecen los apóstoles y santos populares como patro- 
nos de poblaciones, cofradías o gremios, la presencia de san Pablo es puramente testimonial. De estas pocas representaciones se puede decir que en casi su totalidad están basadas en el libro de los Hechos de los Apóstoles o en la Leyenda Dorada y nunca en los textos de sus cartas imprescindibles para actualizar su figura histórica aparte de la hagiografía de las dos fuentes citadas ${ }^{1}$.

En Valladolid esto que se acaba de decir tiene su comprobación. Del riquísimo patrimonio artístico de la ciudad solamente hemos encontrado siete representaciones que presentan una calidad artística regular salvo alguna pequeñísima excepción.

\section{ESCULTURA EXENTA}

La iconografía más popular es la que nos muestra su figura exenta con una espada y un libro. La tradición más conocida es la que narra que Pablo fue martirizado en Roma durante la persecución de Nerón junto con Pedro (lo que ha hecho que los dos apóstoles aparezcan juntos en sus representaciones ${ }^{2}$ ). Según la Leyenda Dorada fue decapitado y arrojada su cabeza a un barranco ${ }^{3}$, lo que dio origen a la presencia de la espada en su iconografía. Junto a la espada (que suele sostener con la mano derecha) también sostiene un libro en alusión a la importancia de sus escritos y a la referencia de la carta a los Efesios en que se afirma "recibid el casco de la salvación y la espada del Espíritu, esto es, la palabra de Dios" (Ef. 6, 17). La figura con esta iconografía en la ciudad de Valladolid tiene una calidad desigual:

- Dos fachadas nos presentan esta representación:

- La iglesia de las Angustias. La iglesia de la penitencial del mismo nombre fue trazada el año 1597 por Juan de Nates (1547 - h. 1613). Entre el equipo del que se rodea para la ejecución de la fachada estaba el escultor Francisco del Rincón $(1657$ - 1608) autor asimismo de las esculturas del retablo de dicha iglesia y de la talla del Cristo de los

\footnotetext{
${ }^{1}$ VIDAL, Senén, Hechos de los Apóstoles y orígenes cristianos. Sal Terrae, Cantabria 2015.

2 Vidal, Senén, Pablo, de Tarso a Roma. Sal Terrae, Cantabria 2007, 205-207.

3 Vorágine, Santiago, La Leyenda Dorada, Vol I, Alianza Forma, Madrid 1984, 357 -371 .
} 


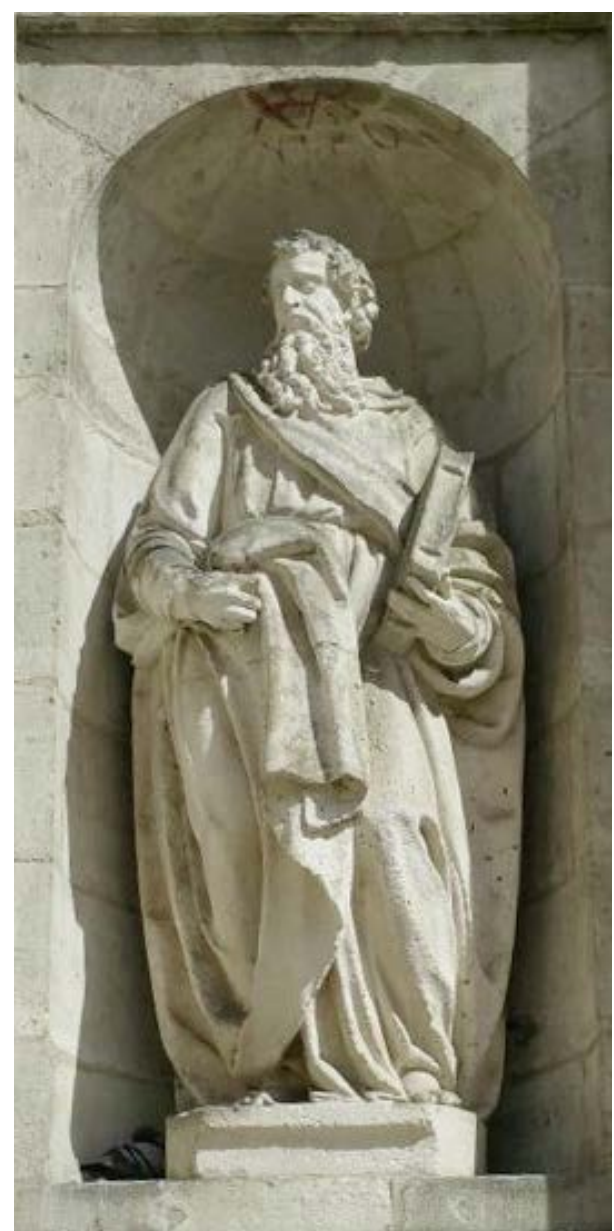

Fachada iglesia de las Angustias

Carboneros del mismo templo $^{4}$. Las diferentes piezas de la fachada aluden a la denominación de la cofradía y a su fiesta principal: la Quinta Angustia y la Anunciación. Sin embargo, en los nichos que flanquean la puerta principal están ocupados por las figuras de San Pedro y San Pablo. Esta se muestra según la iconografía ya citada faltando la espada. Es una pieza de gran calidad obedeciendo al tipo barroco de este escultor precursor de Gregorio Fernández. Presenta una poblada barba con abundantes pliegues en el vestido y el típico movimiento del hombro izquierdo más bajo que el derecho. Es la talla de más calidad de las representadas en piedra de la figura de San Pablo.

- Fachada de la Catedral. La fachada de la sede vallisoletana, al igual que el resto del edificio, obedece a dos épocas distintas debido a su no conclusión 5 . De la parte barroca se ocupó Alberto de Churriguera el año 1729 quien encargo las esculturas de la fachada a Antonio Gautua (para las figuras de los cuatro doctores del cuerpo superior) y a Pedro de Bahamonde (1729-1748) para las esculturas de San Pedro y San Pablo a ambos lados de la fachada principal y la

\footnotetext{
${ }^{4}$ García Martín, Enrique, Los escultores Francisco del Rincón y Gregorio Fernández, Junta de cofradías de Semana Santa, Valladolid 2001, 12-13.

5 Para un estudio del edificio ver UrRea FernándeZ, Jesús, La catedral de Valladolid y el museo diocesano, Ed. Everest, León 1978.
} 
Asunción encima de la puerta principal. La escultura de San Pablo, al igual que la de San Pedro, acusa un notable deterioro: le faltan ambas manos y la espada. Obedecen al barroco del siglo XVIII con gran movimiento y abundancia de pliegues en una etapa en la que este estilo ya se veía reemplazado por el neoclasicismo.

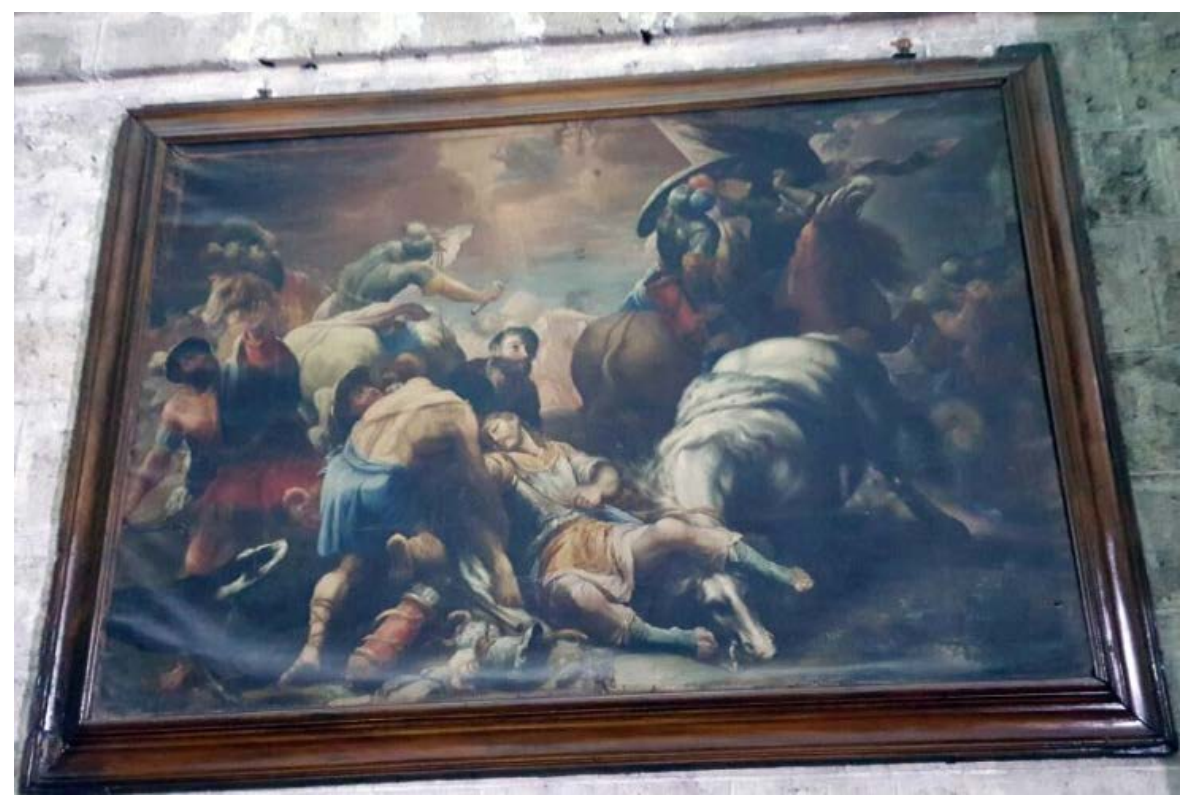

Catedral

- Retablos:

Retablo Mayor de la iglesia de La Magdalena. Esta iglesia, cuyo patrón fue el Obispo Pedro Lagasca, en la que su escudo ocupa toda la fachada y se extiende por doquier en el interior de ella, nos presenta el gran retablo mayor considerado como la obra máxima del escultor Esteban Jordán (h.1530 - 1598). Fue contratado el año 1571 al igual que el sepulcro de alabastro de Gasca en el centro de la iglesia ${ }^{6}$. El retablo consta de banco, tres

6 PARRAdo del Olmo, Jesús María, "Retablo Mayor de la iglesia de La Magdalena de Valladolid", en Arte americanista en Castilla y León. Exposición en Valladolid, Iglesia de la Magdalena, Noviembre-Diciembre 1992, Junta de Castilla y León, Valladolid 1992, 79-80. 
pisos y ático y tres calles. En la calle central se nos muestra en mayor tamaño La Traslación de la Magdalena y a ambos lados en dos hornacinas aparecen en pareja San Pedro y San Pablo, y San Felipe y Santiago respectivamente. San Pablo aparece a la dere-

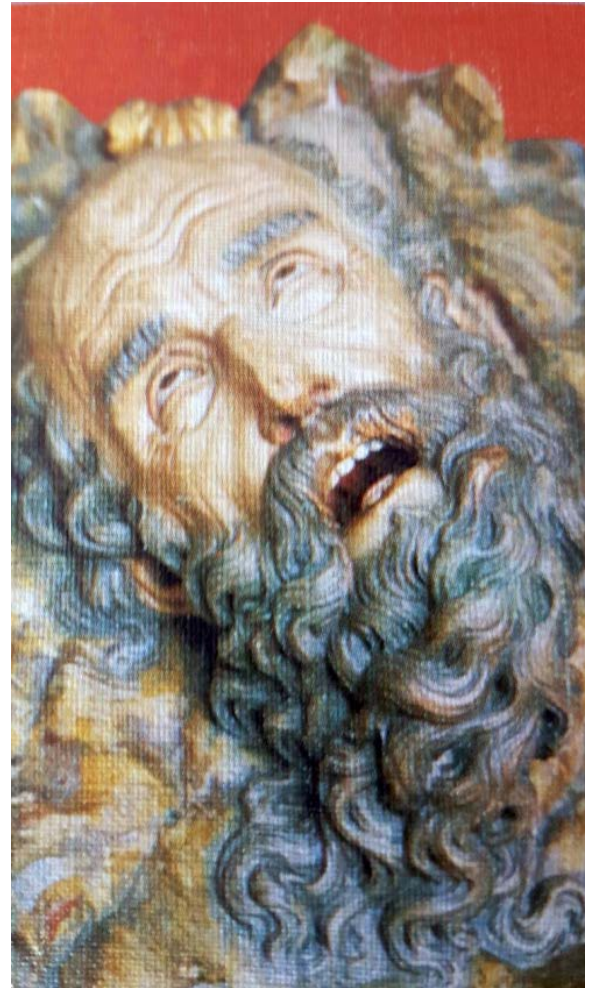

Museo Nacional de Escultura

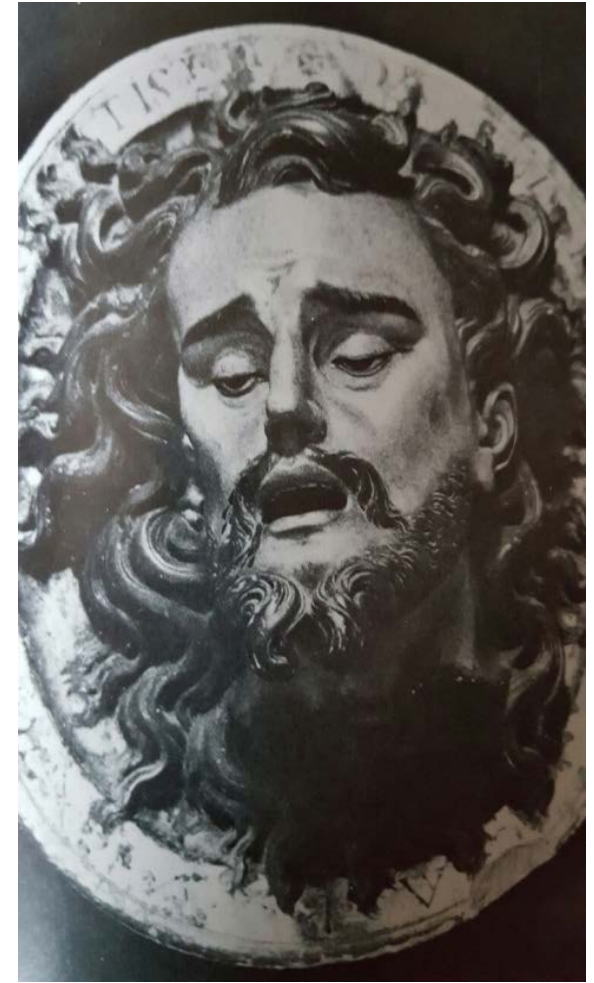

Iglesia San Andrés

cha de San Pedro (cosa extraña pues suele ser al revés). Tiene los atributos del libro y la espada. Conserva buena policromía. Su grandioso tamaño, al igual que todo el retablo, se ve minusvalorado por la composición muy basta que no cuida nada el detalle, de lo que se deduce que fue concebido para ser contemplado de lejos sin ninguna otra ambición estética?

7 MARTín GonzÁlez, Juan José, Juan de Juni y su época. Catálogo de la exposición conmemorativa del IV centenario de la muerte de Juan de Juni celebrada en Valladolid y Madrid en 1977, Ed. Patronato Nacional de Museos, Valladolid-Madrid 1977, 75. 
San Pedro y San Pablo de la iglesia de Jesús. En esta desdichada iglesia de la penitencial de Jesús Nazareno (fue recortada y reedificada la fachada el año 1885 debido al plan urbanístico), acoge a ambos lados del Retablo Mayor de tipo neoclásico, dos esculturas exentas de San Pedro y San Pablo en su característica iconografía. Obra del primer tercio del siglo XVII que serían añadidas al primitivo Retablo Mayor desaparecido el año 17998. Se pueden adjudicar al escultor José de Rozas (†1725) al ser cofrade de Jesús Nazareno9. Al ser colocado el actual retablo el año 1815 las tallas de San Pedro y San Pablo fueron pintadas totalmente de blanco por Anastasio Chicote a imitación de mármol para que hicieran juego con el neoclasicismo del citado retablo. En estos últimos años se intentó devolverlos su policromía original de cuya labor da testimonio su extraño y lamentable aspecto actual al ser devuelta su policromía solamente en las cabezas de ambos quedando el resto blanco.

\section{La conversión de San Pablo}

Este tema, junto con la figura exenta, es el más representado en la iconografía de Pablo. En sus cartas no narra cómo fue el acontecimiento. Solamente afirma que en un momento dado "Dios se dignó revelar a su Hijo en mí" (Gal 2,16) señalando asimismo que fue perseguidor de la "comunidad de Dios" (1 Cor 15,9). Es en el libro de los Hechos de los Apóstoles donde se dan más detalles, no considerados históricos, pero que son los que más han trascendido en la iconografía popular (Hech 9,9;22,12-19) aunque con muchos más detalles como la persecución a los cristianos en Damasco y la revelación con la voz de Dios. Hasta la Edad Media se representa la "visión" de Pablo mientras este camina a pie tal y como se le representa en los mosaicos bizantinos. Para Réau la aparición del caballo obedece a la psicomaquia (representación alegórica de los vicios y virtudes) medieval siendo el caballo el que representa a la soberbia ${ }^{10}$. Esta escena es la que finalmente va a prevalecer en el arte occidental.

8 Martín González, Juan José - Urrea Fernández, Jesús, Catálogo Monumental de Valladolid y su provincia. Vol. XIV. Monumentos religiosos de la ciudad de Valladolid ( $1^{a}$ parte), Institución Cultural Simancas - Diputación de Valladolid, Valladolid 1985, 219.

${ }^{9}$ García Martín, Enrique, "Los escultores y las cofradías", en Imagineros en la Semana Santa y su obra, Junta de Cofradías de Semana Santa, Valladolid 2000, 53.

10 RÉAU, Louis, Iconografía del arte cristiano. Vol VIII, Ed. Serbal, Barcelona 1998, 14. 

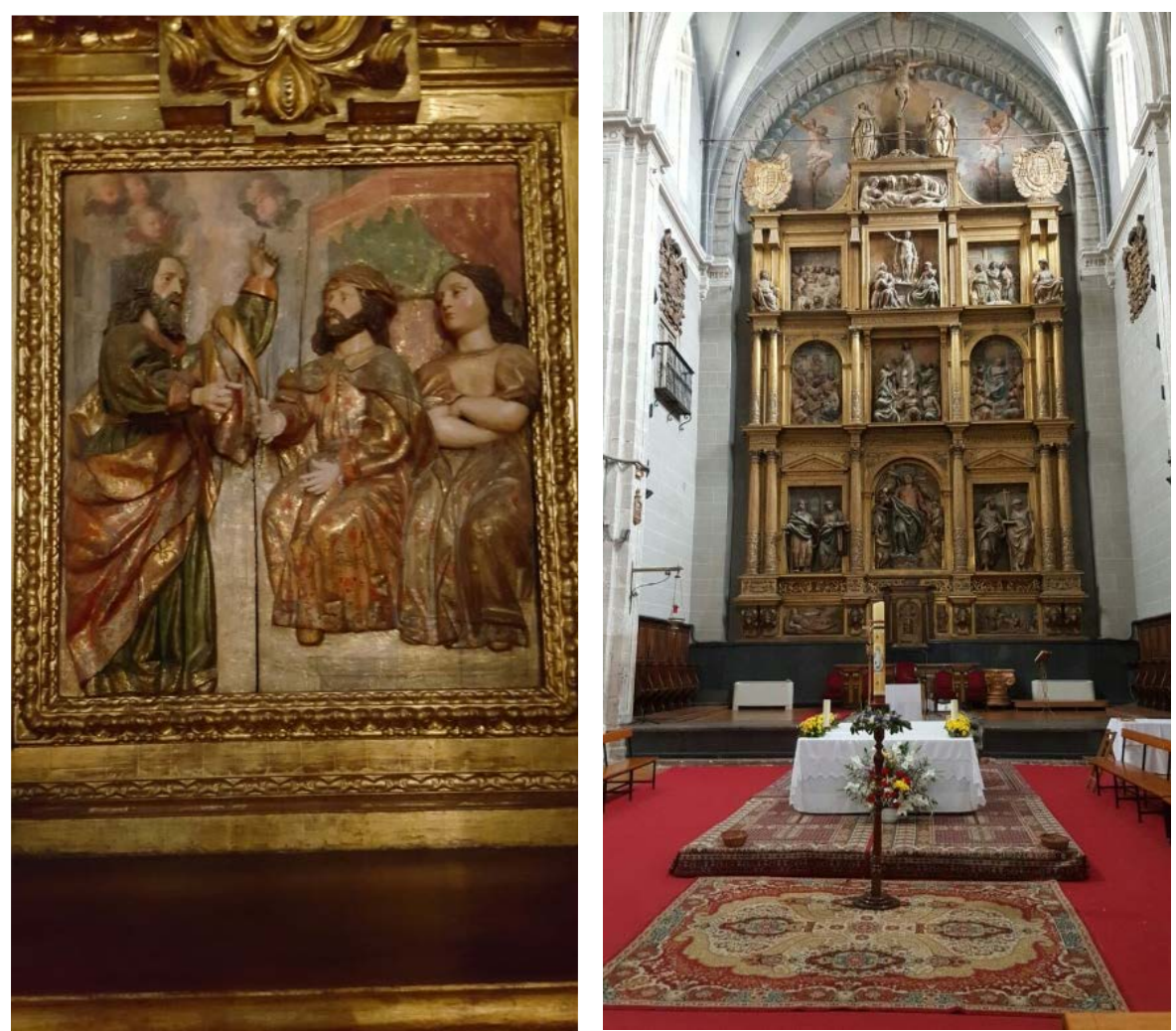

Iglesia San Felipe Neri

Así en Occidente hay dos variantes en el acontecimiento: cayendo del caballo y derribado a los pies del animal. Es esta segunda la que está representada en las escasas pinturas del tema existentes en Valladolid.

- Catedral. En la capilla del Sagrario se nos ofrece un gran lienzo representando el tema. Realizada hacia el año 1700 por Simón Peti el joven (h. 1658-1736). Obedeciendo al último barroco está infinitamente recargada la obra de personajes con gran movimiento. Un Ángel guerrero derriba el caballo de Pablo mientras se aleja en sentido diagonal hacia el vértice derecho de la pintura. Pablo aparece desmayado en el centro del cuadro formando un ángulo con el caballo derribado y sostenido por otros personajes espantados por la visión y la luz procedente del cielo. 
- Convento de San Pablo. Esta pintura, semejante a la vocación de San Pedro de la misma iglesia, procede del antiguo Retablo Mayor cuya traza había sido dada por el escultor Andrés de Solanes en 162811. De este retablo solamente se conservan las dos pinturas citadas y que fueron realizadas por el pintor Bartolomé de Cárdenas (1547-1628). La vocación de San Pedro y La conversión de San Pablo que, al igual que su gemela, es de formato vertical con una composición muy simple: Pablo aparece en el centro derribado del caballo a cuyos lados aparecen personajes en una gran simetría. En la parte de arriba, también en composición simétrica, aparece Jesucristo sobre una nube rodeado de cabezas de ángeles.

\section{Retablo de la iglesia de San Felipe Neri}

En la iglesia de San Felipe Neri, en su retablo mayor, existe una rarísima representación de la vida de Pablo. Dicho retablo consta de tres calles en las que se ubican las figuras de San Felipe Neri en la central, San Pedro en la derecha y San Pablo a la izquierda en su tradicional iconografía. En el banco, bajo la escultura de San Pedro hay un pequeño relieve de San Pedro adorando a Cristo y, bajo la talla de San Pablo aparece un relieve de las mismas dimensiones que el anterior, en el que

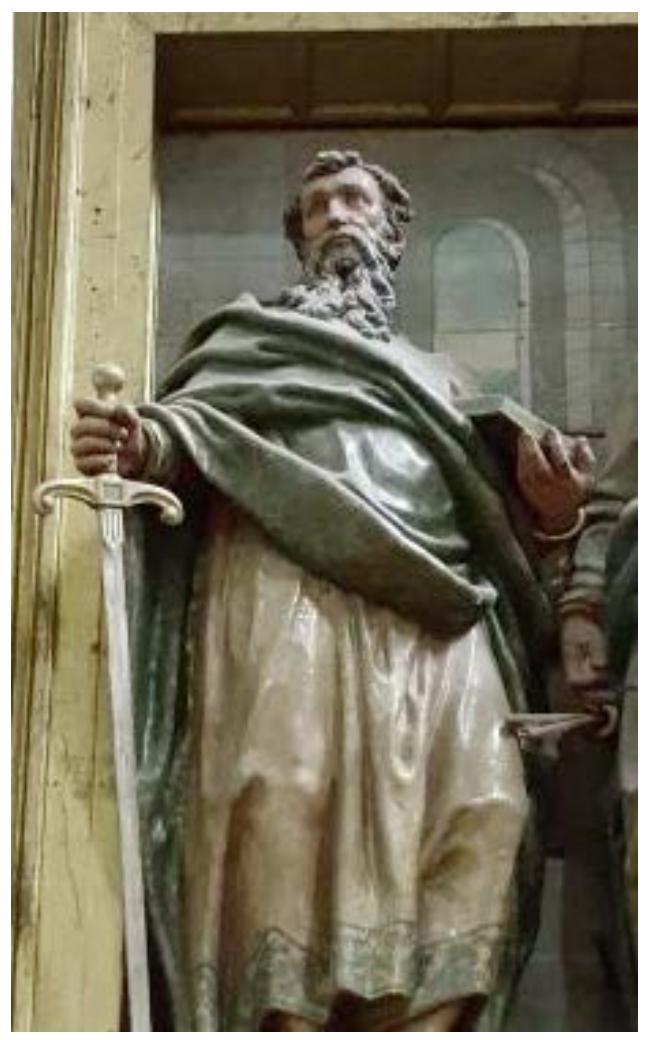

Catedral

11 Urrea, J., El escultor Gregorio Fernández. 1576-1636. (Apuntes para un libro), Universidad de Valladolid, Valladolid 2014, 62-65. 296.

12 Martín González, - Urrea Fernández, Catálogo Monumental de Valladolid, 
están una figura predicando y un hombre y una mujer, sentados, escuchando su predicación.

La representación de este último relieve fue interpretada por Martín González y Jesús Urrea como "Cristo en casa del fariseo" aunque también admitían la posibilidad de Pablo interviniendo ante el gobernador Félix y su mujer Drusila (Hechos 24,24) ${ }^{12}$. Se puede afirmar sin duda ninguna que este pequeño y bello relieve corresponde a la segunda interpretación citada. En primer lugar porque tiene que corresponder a un episodio relacionado con Pablo al estar al pie de su figura y, en segundo lugar por los propios personajes. Pablo es un judío mientras que Félix es un romano y la mujer, con los brazos cruzados escucha atentamente bajo un dosel.

Como se ha dicho es una rarísima iconografía de Pablo. El autor es el escultor Juan de Ávila (activo entre 1678-1704). Considerado como uno de los mejores escultores del siglo XVII, este retablo muestra la verdad de esta opinión. Con expresivos movimientos y sus característicos pliegues a cuchillo hará una escuela de la que formará parte su hijo Pedro13.

\section{Cabeza degollada de San Pablo}

Ya se ha indicado la tradición de la muerte de Pablo por decapitación, de ahí su representación con la espada. Sin embargo va a ser en el barroco cuando este tema va a llegar a su representación más realista y tremendista con las esculturas de la propia cabeza decapitada.

Es por tanto durante el barroco donde se va a representar con el más crudo realismo (no olvidemos que el barroco pretende impactar emocionalmente al espectador) esta cabeza cortada, realismo a que se le añaden los clásicos postizos: ojos de cristal, dientes de pasta, uñas de asta de toro, cristales, espejos...

Considerada como una de las piezas más impactantes de todo el barroco tenemos la cabeza del apóstol conservada en el Museo Nacional de Escultura. Procedente del Convento de San Pablo es obra de Antonio Villabrille y Ron (1663-1726). Realizada el año 1707 es su primera obra y la más conocida ${ }^{14}$. El realismo ya citado barroco se manifiesta en las arrugas

\footnotetext{
13 García Martín, 2000, 33.

14 Martín GonZÁlez, Juan José, Escultura barroca en España, Cátedra, Madrid 1983, 375-377.
} 


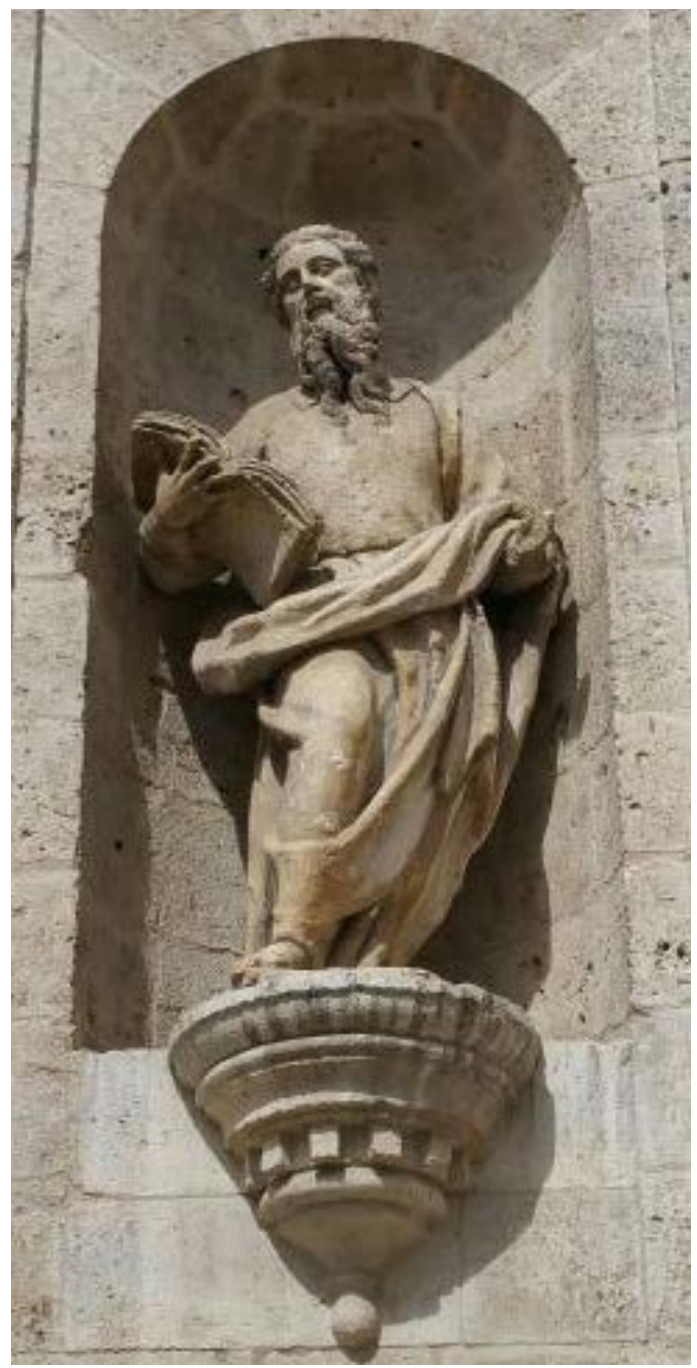

Iglesia de La Magdalena y expresión de la cara, la boca abierta dejando ver la garganta y la campanilla, la lengua casi fuera ensangrentada y dos surcos, uno a cada lado, con recubrimiento de cristal que en su momento simulaban los ríos de sangre que surgieron en el lugar donde la cabeza cortada de Pablo botó en aquel truculento momento.

Esta cabeza ejerció gran fascinación en el escultor tordesillano Felipe Espinabete (1716-1792). Literalmente va a hacer una copia de la misma el año 1760 conservada también en el Museo Nacional de Escultura. Esta iconografía, el mismo escultor, la va a repetir para la obra conservada en la iglesia de san Andrés, en este caso para la cabeza de San Juan Bautista en la que la diferencia está en el plato sobre el que está. 